\title{
Effect of low frequency harvesting in Hevea brasiliensis on major raw rubber properties
}

\author{
K V V S Kudaligama*, V H L Rodrigo*, K M E P Fernando** and \\ P A J Yapa** \\ * Rubber Research Institute of Sri Lanka, Dartonfield, Agalawatta \\ **Department of Botany, University of Sri Jayawardhenapura, Gangodawila, Nugegoda
}

Received 25 October 2012

\begin{abstract}
Harvesting latex, a key activity in the production of natural rubber (NR), involves repeated tapping of the bark on the main trunk of the trees. Low frequency harvesting (LFH) systems are only economically feasible with the use of Ethephon (ET) which stimulates the tree to provide high yield per tap as a compensation for the yield loss due to lowering the tapping frequency. Ethephon concentration and its frequency of application may vary with the frequency of harvesting used. Latex samples were collected from genotypes; RRIC 100, RRIC 102, RRIC 121 and RRIC 130 harvested under $S / 2 d 2, S / 2 d 3, S / 2 d 4$ and $S / 2 d 6$ (i.e. tapping half of the spiral of tree once in two, three, four and six days, respectively) systems were processed into lace crepe and assessed for raw rubber properties viz. initial plasticity $(P o)$, plasticity retention index (PRI), Mooney viscosity $\left(V_{R}\right)$, colour, nitrogen and ash content.

No significant differences were observed among different LFH systems with respect to each raw rubber property tested. However, clonal differences in those raw rubber properties were prominent. Therefore, the study revealed that the low frequency harvesting systems tested with Ethephon stimulation do not have any effect on the quality of raw rubber produced.
\end{abstract}

Key words: Ethephon, low frequency harvesting, natural rubber, raw rubber properties

\section{Introduction}

Although currently the natural rubber (NR) prices are attractive, the survival of the industry is being threatened by price volatility, spiraling cost of production and inadequate supply of skilled harvesters. With the aim of alleviating these problems to a certain degree, adoption of low frequency harvesting (LFH) systems are practiced in the present day context (Karunaichamy et al., 2001; Kewi \& Sivakumaran, 1994; Tasi et al., 1991; Xuehua et al., 2004). Further, LFH 
systems increase the economical life span of the tree with reduced bark consumption. Nevertheless it is necessary that, trees are stimulated under LFH systems for achieving comparable yields to that of traditional $\mathrm{d} 2$ frequency (i.e. harvesting the tree once in two days). Different clones have showed different responses to LFH systems with Ethephon stimulation (Vijayakumar et al., 2004). Level of stimulations to be given may vary with agro climate, genotype, age of trees and frequency of harvesting.

Being a superior quality rubber, crepe rubber is generally used for the manufacture of pharmaceutical products, lighter colour products and rubber based adhesives (Seneviratne \& Sarath Kumara, 2003). Various technological advances made during recent past and the emergence of premium grades of crepe rubber i.e. Lankaprene, escalate the manufacturers' interest on the quality and properties of raw rubber with an aim to maintain the smoothness of manufacturing process as well as the quality of the end product. For crepe rubber and premium grade Lankaprene, specifications for the major properties of dry raw rubber i.e. initial plasticity, plasticity retention index, Mooney viscosity, colour, nitrogen and ash (Table 1) have been stipulated (Seneviratne \& Rathnayake, 2008). Latex produced in most of large scale plantations in Sri Lanka is processed into latex crepe (i.e. $24 \%$ of the annual domestic rubber production) which has given the country the reputation as the world's best quality crepe rubber exporter to the world market (Seneviratne \& Rathnayake, 2008).

The pattern of latex production in the rubber tree varies with the genotype and also with the harvesting system which include both stimulation and harvesting frequency. Nevertheless, only limited studies have been conducted to-date to assess the effects of harvesting systems on the quality of raw rubber. Although particular, no information is available on the effect of Ethephon which is used as the stimulant in LFH systems. Therefore, the study reported here was aimed to assess the effect of the different harvesting frequencies on raw rubber properties of four major Hevea genotypes grown in Sri Lanka.

Table 1. Specification of raw rubber properties of crepe rubber and Lankaprene

\begin{tabular}{lll}
\hline Property & Crepe rubber & Lankaprene \\
\hline Initial plasticity (Wallace units) & 30 (min.) & $35-50$ \\
Plasticity retention index & 60 (min.) & $70-85$ \\
Mooney viscosity (ML $\left.1+4 @ 100^{\circ} \mathrm{C}\right)$ & $75-85$ & $70-80$ \\
Nitrogen \% (w/w) & $0.35(\max )$. & $0.45(\max )$. \\
Ash \% (w/w) & $0.20(\max )$. & $0.25(\max )$. \\
Lovibond colour & $1.5(\max )$. & $1.5(\max )$. \\
\hline
\end{tabular}


K V V S Kudaligama et al.

\section{Materials and Methods}

Mono cropped mature rubber fields with four major genotypes (i.e. RRIC 100, RRIC 102, RRIC 121 and RRIC 130) were selected from the Gallewatta division of Dartonfield estate, Rubber Research Institute (Longitude 80 $00^{\circ} \mathrm{E}$ and Latitude $\left.06^{\circ} 32^{\prime} \mathrm{N}\right)$. Treatment plots comprising 25 trees each were demarcated and four tapping frequencies, $\mathrm{d} 2, \mathrm{~d} 3, \mathrm{~d} 4$ and $\mathrm{d} 6$ (i.e. tapping once in two days, three days, four days and six days, respectively) with half spiral cut $(\mathrm{S} / 2)$ on base panel BI-1 were imposed. No stimulants were used in the traditional system of $\mathrm{S} / 2 \mathrm{~d} 2$ system. Ethephon (2-Chloroethylphosphonic acid) was applied in $\mathrm{S} / 2 \mathrm{~d} 3$ and $\mathrm{S} / 2 \mathrm{~d} 4$ tapping frequencies with $2.5 \%$ concentration, 5 times per year, every two months except defoliation period (ET 2.5\% 5/y) and 3.3\% concentration 12 times per year as monthly applications (ET 3.3\% 12/y), respectively. Application of 5\% Ethephon with every three tappings (ET $5 \%$ 20/y) was done in trees harvested with S/2 d6 tapping system. On average, $1.6 \mathrm{~g}$ of Ethephon solution was applied per tree per application in each harvesting system.

\section{Preparation of rubber samples}

Latex samples (about 2 litres) were collected on monthly basis for three consecutive years in each treatment plot starting from 2008. Samples were coagulated with $1 \%$ formic acid and processed into unfractioned unbleached (UFUB) latex crepe by milling the coagula with 4, 3 and 1 passes in the macerator, diamond and smooth mills, respectively. Rubber laces were dried at $34{ }^{\circ} \mathrm{C}$ in the drying tower and tested for raw rubber properties i.e. initial plasticity (Method - ISO 2007), plasticity retention index (Method - ISO 2930), Mooney viscosity (Method - ISO 289), colour (Method - ISO 4660), nitrogen (Method - ISO 1656) and ash content (Method - ISO 247) using the standard test methods stipulated by the International Standard Organization (Anon, 1984).

Analysis of variance (ANOVA) was made using the statistical package SAS system 9.2 (SAS Institute Inc., USA) to assess the overall impact of harvesting systems on each raw rubber and latex property tested. Further, mean comparison was performed using Duncan's multiple range test. As contents of ash and nitrogen lied below $30 \%$, square root transformation was made for them before the analyses (Gomez \& Gomez, 1984). The raw rubber properties of the traditional $\mathrm{S} / 2$ d2 were used as the standards in evaluation. Further, values were compared descriptively with the standard values stipulated (Table 1) for the production of crepe rubber and Lankaprene.

\section{Results}

Harvesting systems did not show any influence on Po and PRI within the clones $(\mathrm{P}>0.05)$ tested. Initial plasticity was less in RRIC 100 and RRIC 102 when compared to those of RRIC 121 
and RRIC 130 (Fig. 1 \& 2). Initial plasticity value of clone RRIC 121 was above the specifications for Lankaprene under all four harvesting systems. Though not significant, only the crepe rubber produced from latex harvested under $\mathrm{S} / 2 \mathrm{~d} 2$ system was above the maximum stipulated value for Lankaprene in RRIC 130 (Table 1, Fig. $1 \& 2)$.

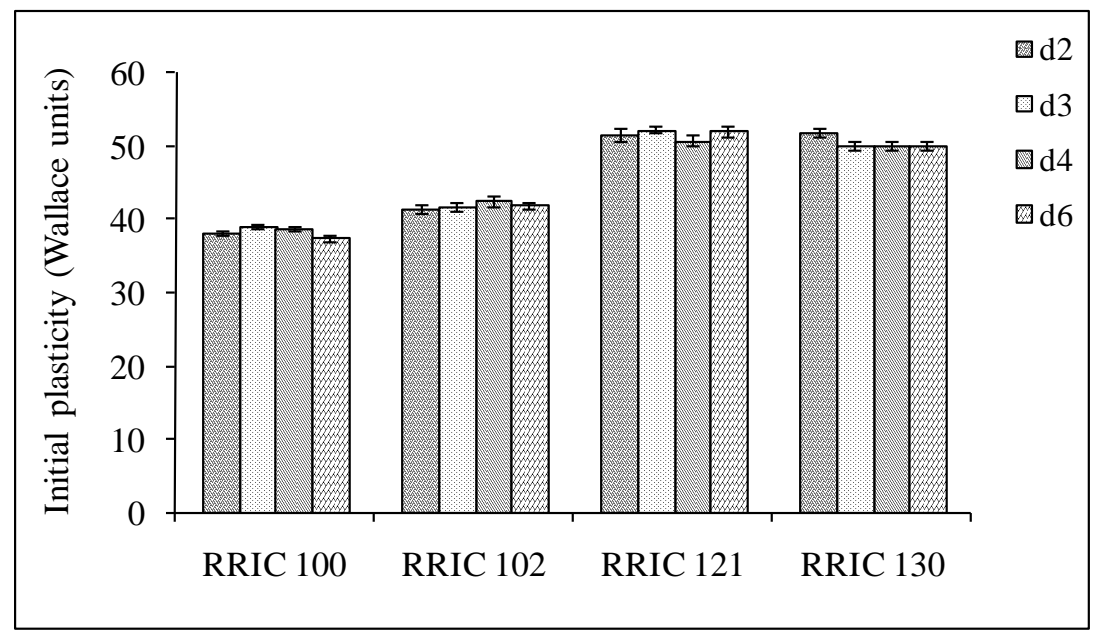

Fig. 1. Initial plasticity of crepe rubber tapped under half spiral based once in two (d2), three (d3), four (d4) and six (d6) days harvesting systems

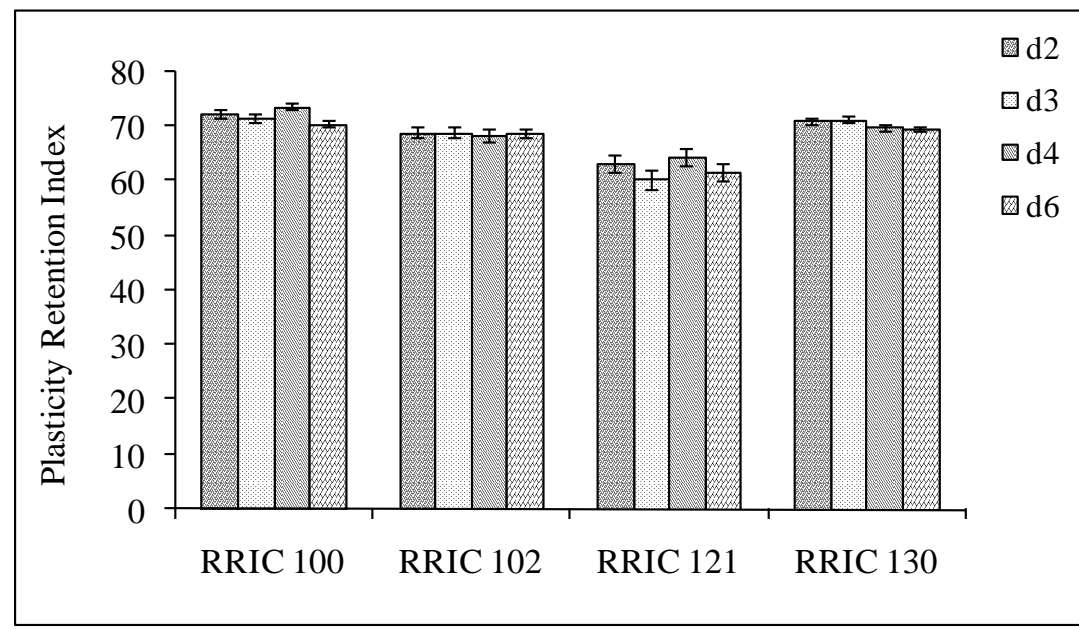

Fig. 2. Plasticity retention index of crepe rubber tapped under half spiral based once in two (d2), three (d3), four (d4) and six (d6) days harvesting systems 
K V V S Kudaligama et al.

In RRIC 100, RRIC 102 and RRIC 130 the PRI values were comparable though the levels in RRIC 121 were little less. In all four genotypes tested no significant variations in PRI value were observed due to harvesting systems (Fig. 2). With the harvesting system tested, all four genotypes were able to meet the specifications of crepe rubber. However, with regard to the specifications of Lankaprene, only RRIC 100 and RRIC 130 were within the limits (Table 1, Fig. 2).

No significant differences $(\mathrm{P}>0.05)$ in Mooney viscosity were observed among the harvesting systems of each clone tested (Fig 3). The highest Mooney viscosity value was observed in RRIC 130 whilst the lowest was in RRIC 100. Out of four genotypes tested, only RRIC 100 and RRIC 102 met the specifications of crepe rubber. Even these two genotypes met the standards for Lankaprene under $\mathrm{d} 2$ and $\mathrm{d} 3$ frequency; however though not significant Mooney viscosity values observed under $\mathrm{d} 4$ and $\mathrm{d} 6$ frequencies were above the maximum stipulated Mooney viscosity value. Neither RRIC 121 nor RRIC 130 met the standard values of both crepe rubber and Lankaprene at any frequency tested (Table 1, Fig. 3).

Lovibond colour of crepe in RRIC 100 and RRIC 102 was higher than that of RRIC 121 and RRIC 130. However, there was no significant difference
( $>0.05$ ) in Lovibond colour among the harvesting systems (Fig.4). Under all four tapping frequencies, Lovibond colour of RRIC 100, RRIC 102 and RRIC 121 had exceeded the standard limits for crepe and Lankaprene. RRIC 130 met the specifications of crepe rubber and also its premium grade Lankaprene (Table 1, Fig 4).

Ash content of crepe rubber harvested from four genotypes tested did not show any significant variation $(\mathrm{p}>0.05)$ among the harvesting frequencies tested. Lowest ash content was observed in clone RRIC 130, whilst the highest was in RRIC 100 (Fig. 5). In all four genotypes, crepe as well as Lankaprene processed with the latex harvested under four tapping frequencies met the specifications (Table 1, Fig. 5).

Nitrogen content of crepe in all four genotypes tested was also not significantly influenced by the different harvesting frequencies (Fig. 6). None of the genotypes tested met the limits stipulated for standard values for crepe. Nitrogen content in crepe of genotype RRIC 100, RRIC 121 and RRIC 130 did not exceed the maximum limit for Lankaprene. However, RRIC 102 clone met the Lankaprene standards only under $\mathrm{d} 4$ and $\mathrm{d} 6$ frequencies. Though not significant, mean values observed under $\mathrm{d} 2$ and $\mathrm{d} 3$ frequencies were little higher (i.e. $0.03 \%$ and $0.01 \%$ ) than the maximum stipulated limit (Table 1, Fig. 6). 


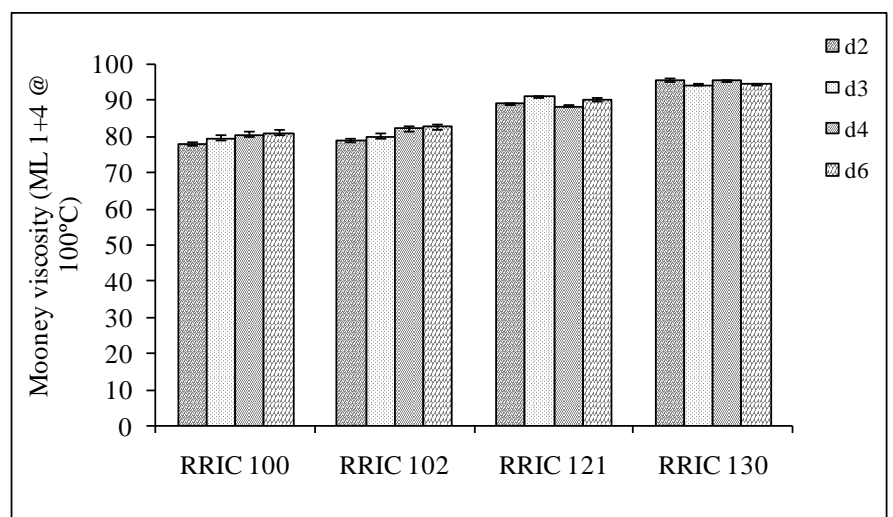

Fig. 3. Mooney viscosity of crepe rubber tapped under half spiral based once in two (d2), three (d3), four (d4) and six (d6) days harvesting systems

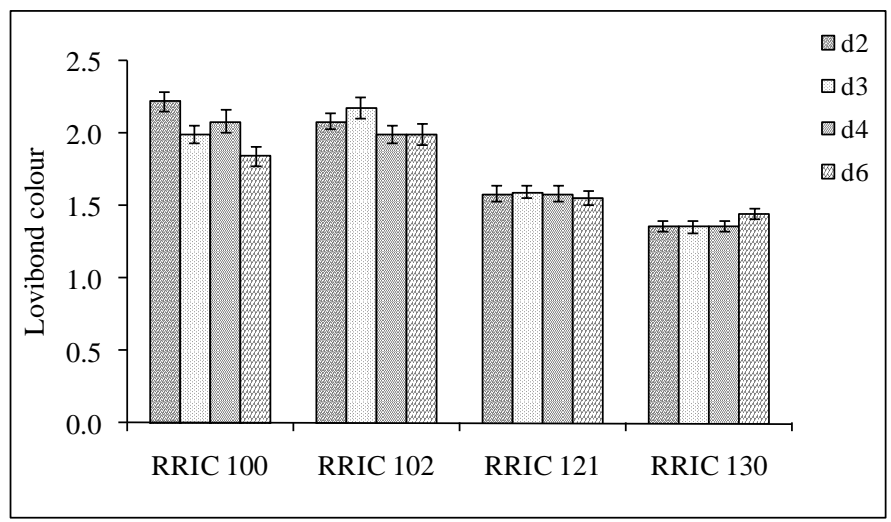

Fig. 4. Colour of crepe rubber tapped under half spiral based once in two (d2), three (d3), four (d4) and six (d6) days harvesting systems

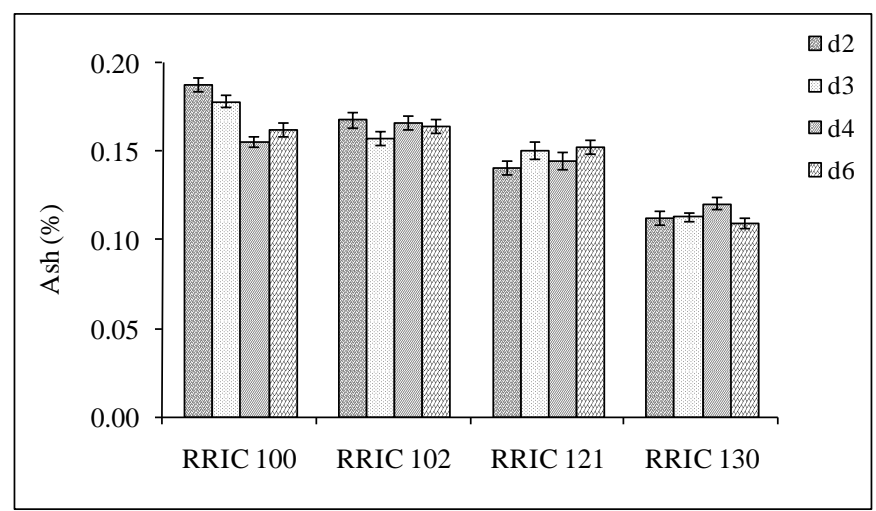

Fig. 5. Ash content of crepe rubber tapped under half spiral based once in two (d2), three (d3), four (d4) and six (d6) days harvesting systems 


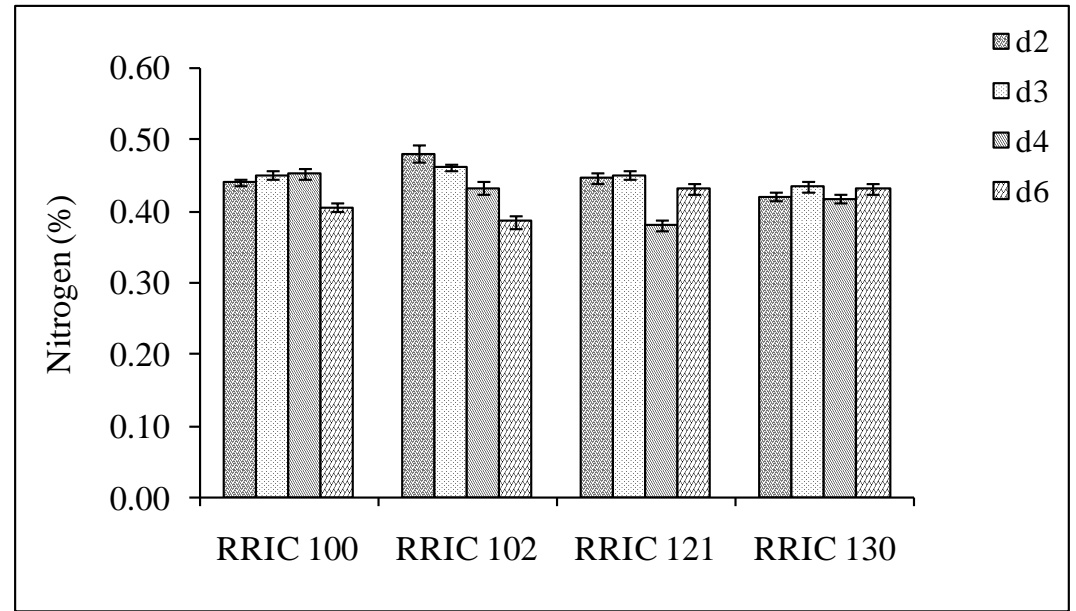

Fig. 6. Nitrogen content of crepe rubber tapped under half spiral based once in two (d2), three (d3), four (d4) and six (d6) days harvesting systems

\section{Discussion}

Latex obtained by tapping the bark of rubber tree contains not only rubber hydrocarbon but also a number of nonrubber substances which include other organic substances such as carbohydrates, lipids, proteins, amines, carotenoids, phenolic substances, etc. and also, some inorganic constituents (George, et al., 2004). Constitution of these substances is primarily a genotypic factor (George, et al., 2004; Yip, 1990) and ultimately has an impact on raw rubber properties of natural rubber directly and indirectly. Ethephon that is used as the stimulant in LFH systems enhances the rubber biosynthesis, making a doubt on its effect on the quality of raw rubber.

Plasticity of the natural rubber varies according to the molecular weight distribution and the gel content of rubber (Eng et al., 2002). Rubber with initial plasticity (Po) below 30 is considered as too soft (Yip, 1990). General Sri Lankan standards for crepe rubber requires a minimum of 30 units for Po (Seneviratne \& Sarath Kumara, 2003) but the requirement for Lankaprene falls between 35-50 units. Initial plasticity of crepe of RRIC 100 and RRIC 102 was within the limits of crepe and Lankaprene. Even though the Po value of RRIC 121 meets the specifications for crepe rubber, it was above the upper limit stipulated for Lankaprene. However non of the LFH systems tested exceeded the limits for Lankaprene. Mooney viscosity $\left(\mathrm{V}_{R}\right)$ of rubber gives an indication about the hardness of rubber and this is very essential to quantify the mechanical work requirement during initial steps of the process line i.e. mixing. Rubber 
with high viscosity may require long pre-mastication period or need expensive peptisers to obtain a workable product (Yip, 1990). Requirement of crepe rubber for Mooney viscosity is within $75-85$ and whilst the limit for premium grade Lankaprene is within 70 - 80. Initial plasticity and Mooney viscosity values of RRIC 121 and RRIC 130 signify that the crepe produced from both genotypes are comparatively harder.

Plasticity Retention Index (PRI) reflects the resistance to oxidative brake down by heating. A high value of PRI denotes high resistance to oxidative brake down. Similar to Po, PRI also varies with the molecular weight distribution and the gel content (Eng et al., 2002). Crepe rubber with PRI above 60 is generally acceptable and hence, stipulated as the minimum value required for latex crepe. However, for Lankaprene, it is to be above 70. Crepe of all four genotypes was above 60 and met the limits of standard Lanka crepe. Only RRIC 100 and RRIC 130 produced crepe with PRI above 70 (limit for Lankaprene) at all harvesting frequencies. Nevertheless, PRI value of RRIC 102 and RRIC 121 genotype was below 70 under all the harvesting frequencies. Results reveal that end products produced from latex of RRIC 100 and RRIC 130 with comparatively higher PRI values are more durable, hence suitable for production of goods that are exposed to higher temperatures and abrasion.

Colour is an essential property in the production of light-coloured goods such as infant teats, catheter tubing, blood tubing, etc. Greater amounts of phenolic substances and carotenoids increase the colour of rubber. Maximum limit for Lovibond colour for both Lankaprene and latex crepe is 1.5 units. However, this limit could be increased up to 3.0 if the colour of the product is not an issue (Seneviratne \& Sarath Kumara, 2003). Although the colour was not affected with the harvesting frequency, only RRIC 130 clone met the maximum limit of colour (without fractionation or bleaching) for both crepe and Lankaprene. However, colour of other three clones could be improved by fractionation and bleaching during manufacturing.

The ash from natural rubber contains varying proportions of oxides, carbonates and phosphates of potassium, calcium, magnesium and trace elements. Additionally, silica or silicates either from rubber or from contaminations will increase the ash content of rubber (Anon, 1970; Yip, 1990). This reflects the mineral content of rubber. Ash content of all four genotypes were below the limits stipulated for crepe and Lankaprene and also was not affected by the harvesting frequency and Ethephon used. Adequate washing during milling reduces the ash content of rubber whilst contaminated chemicals and poor quality water may enhance its level (Seneviratna \& Rathnayake, 2008).

Protein is the major source of nitrogen in rubber. Due to minimal water absorption and low heat built with 
friction, low nitrogen rubber is ideal for special rubber products such as water seals, aircraft tires and bridge bearings. Specially for food and pharmaceutical grades, rubber with minimal amount of leachable proteins is required to minimize the potential allergy problems as those products are in contact with human skin. The maximum nitrogen content stipulated for food and pharmaceutical grade is $0.35 \%$. None of the genotypes have met this limit under unfractioned unbleached status. However, nitrogen content in RRIC 100, RRIC RRIC 121 and RRIC 130 was below $0.45 \%$, the limit stipulated for Lankaprene. Fractionation could be employed to reduce the nitrogen content of rubber to some extent and the treatment of latex with proteolytic enzymes such as papain is another option to bring down the nitrogen content below $0.1 \%$, to produce low nitrogen grades.

No significant differences in raw rubber properties of crepe rubber within a genotypes were observed with different frequencies of latex harvesting. Although the use of Ethephon affects the biosynthesis pathway of rubber, its use in LFH systems has had no effect on the quality of raw rubber. The main objectives of developing the LFH systems were to reduce the labour requirement, cost of production and the bark usage but not to extract higher yields. Maximum amount of Ethephon applied per tree was $1.6 \mathrm{~g}$ of $5 \%$ Ethephon for 20 rounds per year (i.e. $1.6 \mathrm{~g}$ Ethephon per tree per year).
Application of Ethephon in higher doses and/or lower doses with high harvesting frequencies is practiced by some growers, for high yields, particularly at the latter stages of the planting cycle. The effects of such practices on raw rubber properties are not known and therefore need further investigation.

\section{Conclusion}

Low frequency harvesting with Ethephon stimulation targeting the same yields given by the traditional $\mathrm{S} / 2 \mathrm{~d} 2$ system has shown no significant effect on major raw rubber properties of crepe rubber. Nevertheless, the effects of Ethephon application for unsustainable high yields are yet to be studied.

\section{Acknowledgement}

This study was funded by the National Science Foundation under the contract research programme of $\mathrm{RG} / 2006 /$ AG/07. Research activities were conducted with the valuable assistance of the staff of the Department of Biochemistry and Physiology and the Department of Raw Rubber and Chemical Analysis of Rubber Research Institute of Sri Lanka.

\section{References}

Anon (1970). Test methods for standard Malaysian rubbers. SMR Bulletin 7, Rubber Research Institute of Malaysia.

Anon (1984). ISO standards Hand Book 22, Volume 1 \& 2. International Organization of Standardization.

Eng, A H, Chang, C F and Kawahara, S (2002). PRI, ageing and some related properties of constant viscosity natural 
rubbers. Journal of Rubber Research 5(4), 199-208.

George, K M, Sebastian, T, Joseph, R, Thomas, $\mathrm{K} T$, Nair, $\mathrm{R} \mathrm{B}$ and Saraswathyamma, C K (2004). Characterization of latex and rubber from selected Hevea brasiliensis clones. Journal of Natural Rubber Research, 17(1), 23-33.

Gomez, K A and Gomez, A A (1984). Statistical Procedure for Agricultural Research, $2^{\text {nd }}$ edition. John Wiley Sons. Singapore

Karunaichamy, K, Vijayakumar, K R, Thomas, K U, Rajgopal, R and Anil Kumar, D (2001). Response of rubber trees (Hevea brasiliensis Muell. Arg. clone RRII 105) to low frequency tapping (LFT) systems. Indian Journal of Natural Rubber Research 14(2), 7989.

Kewi, Chong and Sivakumaran, S (1994). Performance of low-frequency tapping systems. Proceedings of the Workshop of the Exploitation Technologies to Address Current Labour Problems in the Rubber Industry, December 1994, Kuala Lumpur, Malaysia. pp. 47-67.

Nugawela A, Peries, M R C, Wijesekera, S and Samarasekera, R K (2000). Evaluation of $d / 3$ tapping with stimulation to alleviate problems related to d/2 tapping of Hevea. Journal of the Rubber Research Institute of Sri Lanka 83, 49-61.

Rodrigo, V H L, Wickramarathna, N A A D and Vidanapathirana, R D (2004). Productivity and tapper shortage in rubber plantations; Low frequency tapping can address the shortage of tappers in rubber plantations of Sri Lanka. Proceedings of the First Symposium on Plantation Crop
Research, July 8-9, 2004, Colombo, Sri Lanka, pp. 32-42.

Rodrigo, V H L (2009). Exploitation methods to sustain high performance under changing scenarios. Proceedings of the Centennial Rubber Conference, 12-13 May, Colombo, Sri Lanka, pp. 29-31.

Seneviratne, W M G and Sarath Kumara, P H (2003). Pale crepe and sole crepe. Handbook of Rubber Processing Technology, (Eds. L M K Tillekeratne, A Nugawela and W M G Seneviratne), pp 33-58. Rubber Research Institute of Sri Lanka, Agalawatta, Sri Lanaka.

Seneviratne, W M G and Rathnayaka, U N (2008). Lankaprene: Newly developed premium grade of latex crepe. Proceedings of the Second Symposium on Plantation Crop Research, 16-17 October. Colombo, Sri Lanka, pp. 5562.

Tasi, A Z M, Kewi, C and Hashim, I (1991). Low intensity tapping systems and early use of CUT. In: Towards Greater Viability of the Natural Rubber Industry, Proceedings of the Rubber Growers' Conference, July, Kuala Lumpur, Malaysia, pp. 189-211.

Vijayakumar, K R, Thomas, K U, Rajagopal, $\mathrm{R}$ and Karunaichamy, $\mathrm{K}$ (2004). Successful extension of low frequency tapping in different agroclimates and report on high yield under 1/2S D/6 6D/7 tapping. Proceedings of the International Rubber Research and Development Board Conference, 7-8 September 2004. Kunming, China, pp. 12.

Vijayakumar, K R (2003). Low frequency tapping to reduce cost of natural rubber production. Indian Rubber Journal 70, 41-42. 
K V V S Kudaligama et al.

Xuehua, L U O, Yunqing, L I U, Xiujuan, C A I, Juqun, W U and Bixia, Z H O U (2004). Effect of different tapping systems on the mineral nutrient of latex total solids of RRIM 600 tree. Proceedings of the International Rubber Research and Development Board Conference, 7-8 September. Kunming, China, pp. 8.
Yip, Esah (1990). Clonal characterization of latex and rubber properties. Journal of Natural Rubber Research 5(1), 52-80.

Address for correspondence: Mrs K V V S Kudaligama, Research Officer, Biochemistry \& Physiology Dept., Rubber Research Institute of Sri Lanka, Dartonfield, Agalawatta, Sri Lanka.

e-mail:vskudaligama@yahoo.com 